\title{
Engineering of Escherichia coli to facilitate efficient utilization of isomaltose and panose in industrial glucose feedstock
}

\author{
Kenji Abe $^{1,2} \cdot$ Akio Kuroda $^{2}$ Ryo Takeshita ${ }^{1}$
}

Received: 29 July 2016 /Revised: 27 October 2016 / Accepted: 26 November 2016 /Published online: 8 December 2016

(C) The Author(s) 2016. This article is published with open access at Springerlink.com

\begin{abstract}
Industrial glucose feedstock prepared by enzymatic digestion of starch typically contains significant amounts of disaccharides such as maltose and isomaltose and trisaccharides such as maltotriose and panose. Maltose and maltosaccharides can be utilized in Escherichia coli fermentation using industrial glucose feedstock because there is an intrinsic assimilation pathway for these sugars. However, saccharides that contain $\alpha-1,6$ bonds, such as isomaltose and panose, are still present after fermentation because there is no metabolic pathway for these sugars. To facilitate more efficient utilization of glucose feedstock, we introduced $g l v A$, which encodes phospho- $\alpha$-glucosidase, and $g l v C$, which encodes a subunit of the phosphoenolpyruvate-dependent maltose phosphotransferase system (PTS) of Bacillus subtilis, into E. coli. The heterologous expression of $g l v A$ and $g l v C$ conferred upon the recombinant the ability to assimilate isomaltose and panose. The recombinant $E$. coli assimilated not only other disaccharides but also trisaccharides, including alcohol forms of these saccharides, such as isomaltitol. To the best of our knowledge, this is the first report to show the involvement of the microbial PTS in the assimilation of trisaccharides. Furthermore, we demonstrated that an L-lysineproducing $E$. coli harboring glvA and $g l v C$ converted
\end{abstract}

Kenji Abe

kenji_abe68@ajinomoto.com

1 Process Development Laboratories, Research Institute for Bioscience Products \& Fine Chemicals, Ajinomoto Co., Inc., 1-1 Suzuki-cho, Kawasaki-ku, Kawasaki-shi, Kanagawa 210-8681, Japan

2 Department of Molecular Biotechnology, Graduate School of Advanced Sciences of Matter, Hiroshima University, 1-3-1 Kagamiyama, Higashi-Hiroshima-shi, Hiroshima 739-8530, Japan isomaltose and panose to L-lysine efficiently. These findings are expected to be beneficial for industrial fermentation.

Keywords Escherichia coli $\cdot$ Maltose $\cdot$ Isomaltose $\cdot$ Panose · Assimilation $\cdot g l v A \cdot g l v C \cdot$ Bacillus subtilis $\cdot$ L-Lysine production

\section{Introduction}

In the industrial production of useful compounds by fermentation, glucose is one of the most frequently used carbon sources (Peters 2007). Industrial glucose feedstock is prepared from starch, a polysaccharide composed of glucose units linked together by $\alpha-1,4$ and $\alpha-1,6$ glycoside bonds, by means of enzymatic hydrolysis (Martin and Smith 1995; Hii et al. 2012). Complete hydrolysis of starch into glucose adds significant cost; therefore, most commercially available glucose feedstock is processed incompletely (Gokarn et al. 2014). Because of incomplete enzymatic hydrolysis and/or reverse reactions, the glucose feedstock contains significant amounts of maltose [4-O- $\alpha$-D-glucopyranosyl-D-glucopyranose] (1$2 \%$ ), isomaltose [6-O- $\alpha$-D-glucopyranosyl-D-glucopyranose] $(0.5-2 \%)$, and other oligosaccharides, such as panose [ $\alpha$-Dglucopyranosyl-(1->6)- $\alpha$-D-glucopyranosyl-(1->4)-D-glucopyranose] (1\% or less) (Hii et al. 2012; Gokarn et al. 2014; Hassan et al. 1998; Crabb and Shetty 1999; Sierkes and Svensson 1992; Takasaki 1988; Chaplin and Bucke 1994). If microorganisms used for fermentation cannot metabolize these saccharides, valuable carbohydrates would be wasted.

Escherichia coli is the most useful bacterial strain for the production of valuable compounds, such as amino acids and organic acids, because $E$. coli cells grow quickly, rapidly convert substrates to products, and are readily genetically engineered (Leuchtenberger et al. 2005; Wendisch et al. 
2006). For example, L-lysine, which is used as a feed additive worldwide, is produced on the scale of approximately $1,500,000$ t per year (Doi et al. 2014). However, saccharides that contain $\alpha-1,6$ bonds, such as isomaltose and panose, are not used up during $E$. coli fermentation because $E$. coli cannot assimilate isomaltose and panose as carbon sources. Furthermore, these sugars, which contain reducing sugar moieties, can react with free amino groups of amino acids during the purification step (Smuda and Glomb 2011; Ledl and Schleicher 1990); this so-called Maillard reaction decreases the yield of the final product and contaminates the reaction mixture with undesirable compounds. These problems must be overcome in order to increase the yield and productivity of fermentation when using glucose feedstock as a carbon source.

The phosphotransferase system (PTS) is responsible for the transport and phosphorylation of sugars. The multicomponent PTS comprises a phosphohistidine carrier protein (HPr), an enzyme I (EI) component, and a membrane-bound enzyme complex (EII). The HPr and EI components transfer a phosphoryl group of phosphoenolpyruvate (PEP) to the sugar-specific enzymes EIIA and EIIB. EIIC is an integral membrane protein permease that recognizes and transports the sugar, which is then phosphorylated by EIIB (Postma et al. 1993). There are 21 different EII complexes encoded in the E. coli chromosome; these complexes are involved in the transport of approximately 20 different carbohydrates (Escalante et al. 2012). Pikis et al. reported that the heterologous expression of Klebsiella pneumoniae aglA (a singlechain polypeptide of EIIC and EIIB that mediates the transport and phosphorylation of sucrose and various other $\alpha$ linked glucosides) and $a g l B$ (a phospho- $\alpha$-glucosidase) confers upon $E$. coli cells the ability to utilize isomaltose (Pikis et al. 2006; Thompson et al. 2001). Although E. coli K-12 strains have homologs of aglA and aglB (Thompson et al. 2001), these seemed to be cryptic or nonfunctional truncated proteins (Reizer 1994; Thompson et al. 1995). However, Bacillus subtilis strains, which are generally regarded as safe (GRAS) organisms by the Food and Drug Administration (FDA) (Harwood and Wipat 1996; Singh et al. 2009; Song et al. 2016; Zeigler et al. 2008), have $g l v A$ and $g l v C$, functional homologs of $a g l B$ and $a g l A$, respectively (Thompson et al. 2001). GlvA and GlvC are known to be involved in maltose assimilation in $B$. subtilis (Yamamoto et al. 2001; Thompson et al. 1998). Although a wide variety of phosphorylated $\alpha$-linked aryl glucosides can be degraded by GlvA (Yip et al. 2007), there are no other reports describing its substrate specificity.

In this study, we found that the heterologous expression of $g l v A$ and $g l v C$ conferred upon E. coli cells the ability to assimilate isomaltose. Unexpectedly, the recombinant also assimilated trisaccharides containing $\alpha-1,6$ bonds, such as panose, as well as the alcohol forms of these saccharides, such as isomaltitol. Our results may facilitate increased production yields using glucose feedstock in industrial-scale fermentation by E. coli.

\section{Materials and methods}

Bacterial strains, plasmids, and primers All strains, plasmids, and primers used in this study are listed in Tables 1 and 2 .

Table 1 Strains and plasmids used in this study

\begin{tabular}{|c|c|c|}
\hline Strain or plasmid & Description, genotype, or sequence & Reference, source \\
\hline \multicolumn{3}{|l|}{ Strains } \\
\hline E. coli $\mathrm{K}-12 \mathrm{MG} 1655$ & $\mathrm{~F}^{-} 1^{-} i l v G r f b-50 r p h-1$ & CGSC Collection \\
\hline E. coli WC196LC & $\begin{array}{l}\text { W3110 NTG mutant (S-aminoethyl-L-cysteine-resistant mutant) } \\
\quad \Delta l d c \Delta c a d A\end{array}$ & Kikuchi et al. (1997) \\
\hline Bacillus subtilis 168 & $\operatorname{trp} C 2$ ypqP::SP $\beta$ & Zeigler et al. (2008) \\
\hline MG1655 (empty vector) & E. coli K-12 MG1655 harboring pTWV229 and pMW219- $\Delta$ plac & This study \\
\hline MG1655 (glvAC) & $\begin{array}{l}\text { E. coli K-12 MG1655 harboring pTWV229-self-glvA-Fw and } \\
\text { pMW219- } \Delta \text { Plac-*tac-glvC }\end{array}$ & This study \\
\hline WC196LC (pCABD2) & E. coli WC196LC harboring pCABD2 & $\begin{array}{l}\text { Kojima et al. (1994); Kikuchi } \\
\text { et al. (1997); Doi et al. (2014) }\end{array}$ \\
\hline \multicolumn{3}{|l|}{ Plasmids } \\
\hline pTWV229 & Cloning vector, $\mathrm{Ap}^{\mathrm{r}}$ & Takara Bio Inc., (Japan) \\
\hline pMW219 & Cloning vector, $\mathrm{Km}^{\mathrm{r}}$ & Nippon Gene Co. Ltd. (Japan) \\
\hline pMW219- $\Delta$ Plac & pMW219 derivative lacking the lac promoter region & This study \\
\hline pMW219- $\Delta$ Plac-tac-glvC-R2 & pMW219- $\Delta$ Plac derivative harboring the Ptac-glv $C$ gene & This study \\
\hline pMW219- $\Delta$ Plac-Ptac4075-glvC-Rv & pMW219- $\Delta$ Plac derivative harboring the Ptac4075-glvC gene & This study \\
\hline pTWV229-self-glvA-Fw & pTWV229 derivative harboring the Pself-glvA gene & This study \\
\hline pMW219- $\Delta$ Plac-*tac-glvC & $\begin{array}{l}\text { pMW219- } \Delta \text { Plac-tac-glvC-R2 derivative harboring a mutation in } \\
\text { the }-10 \text { region of the tac promoter (TATAAT to AATAAT) }\end{array}$ & This study \\
\hline pCABD2 & $\begin{array}{l}\text { pRSF1010 harboring mutated lys } C, \text { mutated } d a p A, \text { mutated } d a p B \text {, } \\
\text { and } C . \text { glutamicum } d d h\end{array}$ & Kojima et al. (1994) \\
\hline
\end{tabular}


Table 2 Primers used in this study

\begin{tabular}{ll}
\hline Primer & Sequence \\
\hline pMW119-F-Hind3 & GCCAAGCTTGCATGCCTGCAGGTCGACTCTAGAGG \\
pMW119-R-Hind3 & CCCAAGCTTGCTAACTCACATTAATTGCGTTG \\
pTWV229-F-Hind3 & GCCAAGCTTGCATGCCTGCAGGTCGACTCTAGAGG \\
pTWV229-R-Hind3 & CCCAAGCTTCACATTACTTGGCAGAACATATCC \\
glvC-F-tac & CAATTTCACACAAGGAGACTGCCATGATGCAAAAAATTCAGCG \\
glvC-R2 & CCCAAGCTTCCCCTTTTTACTCGATTGTCTC \\
tac-promoter-glvC-1 & CGTATAATGTGTGGAATCGTGAGCGGATAACAATTTCACACAAGGAGACT \\
& GCCATGATGCAAAAAATTCAGCGCTTTGGA \\
Hind3-tac-promoter & CCCAAGCTTCCTGTTGACAATTAATCATCGGCTCGTATAATGTGTGGAAT \\
tac-promoter-glvC-2 & CGATTAAGCGGATAACAATTCACACAAGGAG \\
glvA-self-Fw1 & GCCATGATGCAAAAAATTCAGCGCTTTGGA \\
glvA-self-Rv1 & TGTAGTGCTGATCCCGCTCTATGG \\
\hline
\end{tabular}

HindIII recognition site was underlined
Construction of vectors The plasmid pMW219- $\Delta$ Plac was constructed by deleting the lac promoter from the vector plasmid pMW219 (Nippon Gene Co., Ltd., Tokyo, Japan) as follows. A DNA fragment was amplified using the primer set pMW119-F-Hind3 and pMW119-R-Hind3, and HindIII/ PstI-digested pMW219 was used as a template. The polymerase chain reaction (PCR)-amplified fragment was digested by HindIII and subsequently self-ligated by DNA ligase. E. coli JM109 competent cells were transformed with the DNA, and transformants were selected on LB agar medium containing kanamycin.

Construction of $\boldsymbol{g} \boldsymbol{l} \boldsymbol{c} \boldsymbol{C}$-expressing plasmids A DNA fragment containing $g l v C$ was amplified by PCR with the primer set glvC-F-tac and glvC-R2 and with the B. subtilis 168 genome as a template. In order to add a promoter sequence upstream of $g l v C$, the amplified DNA fragment containing $g l v C$ and synthetic single-strand DNA (tac-promoter-glvC-1) were mixed, and another PCR was then carried out using the primer set Hind3tac-promoter, glvC-R2. The amplified DNA fragment and SmaI-digested pMW219- $\Delta$ Plac were ligated by DNA ligase. The plasmid pMW219- $\Delta$ Plac-glvC-R2 was extracted from transformants, and its structure was confirmed. The plasmid pMW219- $\Delta$ Plac-Ptac4075-glvC-Rv containing $g l v C$ under the control of the tac promoter variant Ptac4075, which was a weaker promoter than tac promoter because of a mutation in the consensus sequence, was constructed in a similar manner using primers Hind3-tac-promoter, glvC-R2, and synthetic DNA, tac-promoter-glvC-2.

Construction of $\boldsymbol{g} \boldsymbol{l} \boldsymbol{v} \boldsymbol{A}$-expressing plasmid A DNA fragment containing $g l v A$ and its upstream region containing a promoter sequence was amplified by PCR with the primer set glvA-selfFw1 and glvA-self-Rv1 and with the B. subtilis 168 genome as a template. The PCR-amplified DNA and SmaI-digested pTWV229 were ligated by DNA ligase. In the resulting plasmid, pTWV229-self-glvA-Fw, glvA mRNA was transcribed via the lac promoter of pTWV229.

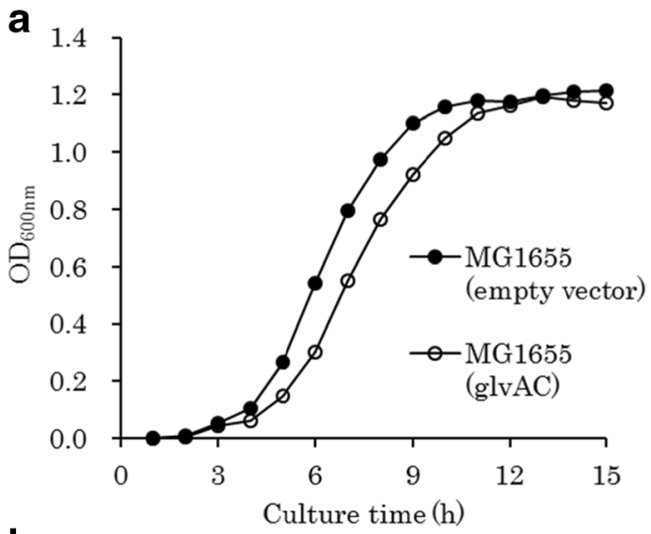

b

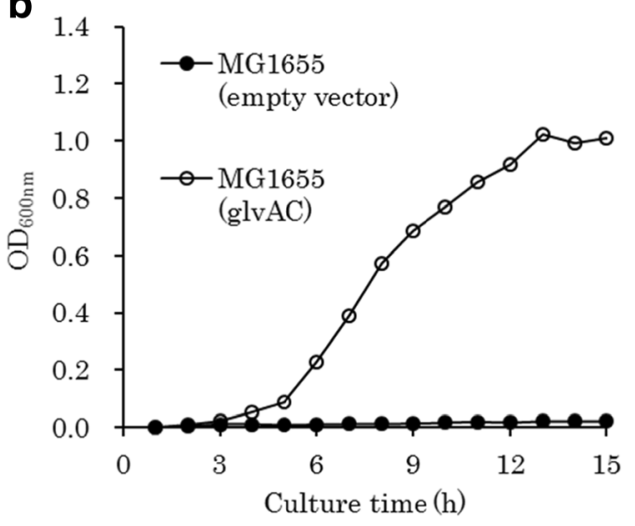

Fig. 1 Growth curves of E. coli strains on M9-glucose (a) and M9isomaltose (b). Each point in the curve represents the mean of two independent experiments 
Assimilation test in M9 minimal medium M9 liquid minimal medium (Miller 1992) supplemented with $2 \mathrm{~g} / \mathrm{L}$ isomaltose or maltose was used for assimilation tests. $E$. coli strains were precultured overnight at $37{ }^{\circ} \mathrm{C}$ on LB medium. The cells were washed three times with cold saline and adjusted to an $\mathrm{OD}_{620}$ of 7.0. The cell suspension $(70 \mu \mathrm{L})$ was added to $5 \mathrm{~mL}$ M9 minimal medium in an L-shaped test tube and cultured at $37{ }^{\circ} \mathrm{C}$ with shaking at $70 \mathrm{rpm}$ using a BioPhotorecorder (TN-1506; Advantec, Inc., Tokyo, Japan). In all experiments, appropriate antibiotics were added to the medium. M9 solid minimal medium (Miller 1992) supplemented with $2 \mathrm{~g} / \mathrm{L}$ of various types of sugars and sugar alcohols was used for assimilation tests. E. coli strains were precultured overnight at $37{ }^{\circ} \mathrm{C}$ on LB medium. The cells were washed three times by cold saline and adjusted to $\mathrm{OD}_{620}$ of 5.0. The cell suspension $(20 \mu \mathrm{L})$ was inoculated on M9 minimal medium plates containing various types of sugars and sugar alcohols and incubated at $37{ }^{\circ} \mathrm{C}$ for $48 \mathrm{~h}$. Glucose and sucrose were purchased from Junsei Chemical Co., Ltd. (Tokyo, Japan). Maltose was purchased from Nacalai Tesque, Inc. (Kyoto, Japan). $\alpha$-Methyl-glucoside was purchased from Wako Pure Chemical Industries, Ltd. (Osaka, Japan).
Isomaltulose, maltotriitol, isomaltitol, lactitol, and erlose were purchased from Hayashibara Co., Ltd. (Okayama, Japan). Isomaltose, panose, isomaltotriose, maltitol, trehalose, turanose, maltulose, galactinol, cellobiose, gentiobiose, lactose, melibiose, lactulose, maltotriose, maltotetraose, maltopentaose, and raffinose were purchased from Tokyo Chemical Industry Co., Ltd. (Tokyo, Japan). For solid medium, $15 \mathrm{~g} / \mathrm{L}$ Bacto agar (Becton Dickinson and Company, USA) was added.

Assimilation tests for maltose and isomaltose in the presence of glucose $E$. coli MG1655 harboring pTWV229-selfglvA-Fw and pMW219- $\Delta$ Plac-*tac-glvC (obtained by an unintended mutation, as described in the "Results" section) was inoculated into M9 minimal medium containing $1.0 \mathrm{~g} / \mathrm{L}$ maltose or isomaltose combined with $1.0 \mathrm{~g} / \mathrm{L}$ glucose. Cells were then cultured at $37{ }^{\circ} \mathrm{C}$ with shaking at $70 \mathrm{rpm}$ using a BioPhotorecorder (Advantec), and sugar concentrations were assayed.

L-Lysine production using glucose, maltose, isomaltose, and panose as carbon sources The L-lysine-producing strain

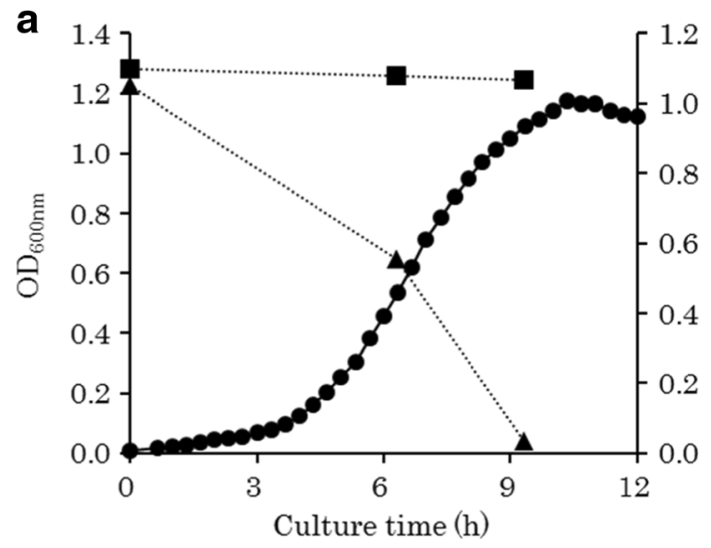

b

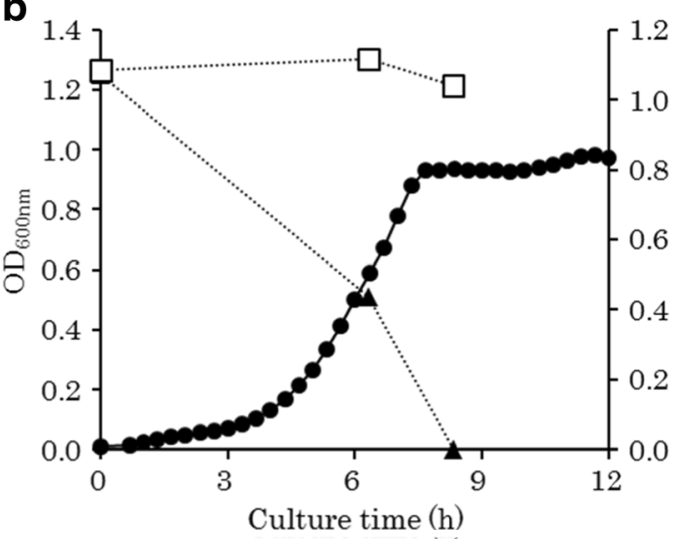

Fig. 2 Growth curves of E. coli recombinants on M9-glucose-maltose or M9-glucose-isomaltose. a MG1655 (empty vector) on M9-glucosemaltose. b MG1655 (empty vector) on M9-glucose-isomaltose. c MG1655 (glvAC) on M9-glucose-maltose. d MG1655 (glvAC) on M9-
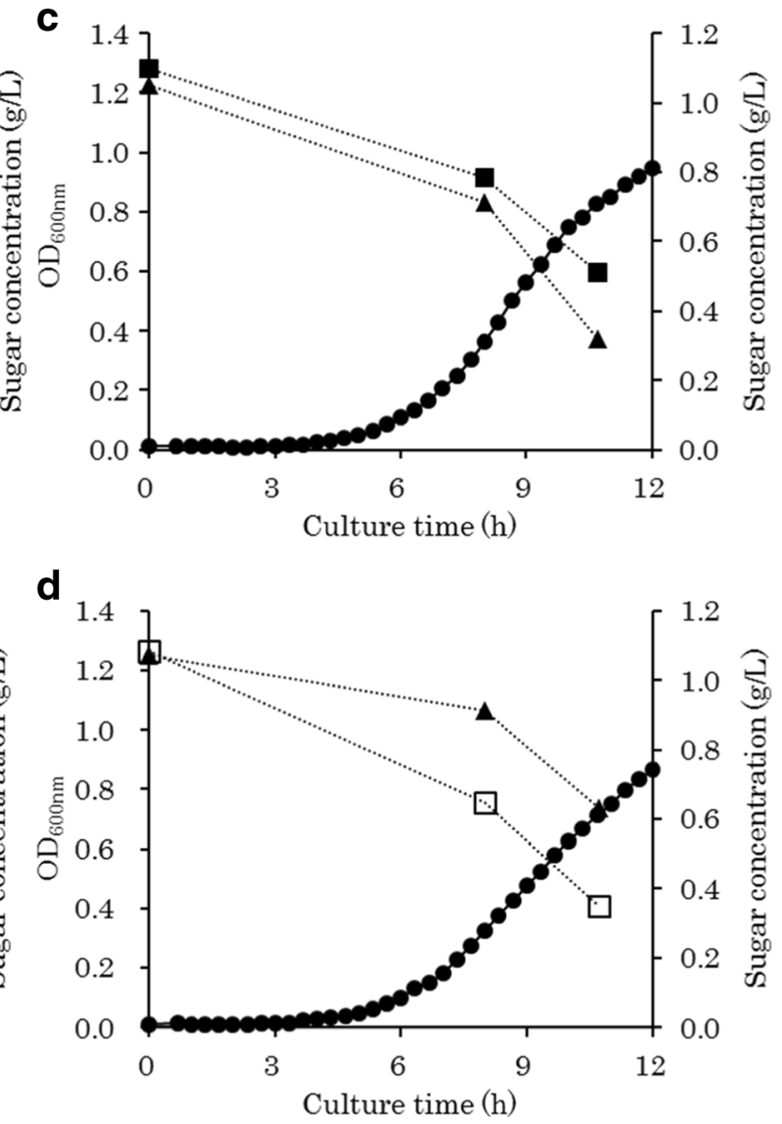

glucose-isomaltose. Cell growth (closed circle), glucose concentration (closed triangle), maltose concentration (closed square), isomaltose concentration (open square) 
Table 3 Growth of E. coli recombinants on selected sugars

\begin{tabular}{|c|c|c|c|c|c|}
\hline Substrate & $\mathrm{DP}$ & Form & $\begin{array}{l}\text { MG1655 } \\
\text { (empty vector) }\end{array}$ & $\begin{array}{l}\text { MG1655 } \\
\text { (glvAC) }\end{array}$ & $\begin{array}{l}\text { MG1655 (pAP2) } \\
\text { (Pikis et al. 2006) }\end{array}$ \\
\hline Glucose & 1 & Sugar & ++ & ++ & ++ \\
\hline$\alpha$-Methyl-glucoside & 1 & Sugar & NDG & ++ & ++ \\
\hline Sucrose & 2 & Sugar & NDG & ++ & - \\
\hline Maltose & 2 & Sugar & ++ & ++ & ++ \\
\hline Isomaltose & 2 & Sugar & NDG & ++ & ++ \\
\hline Maltitol & 2 & $\begin{array}{l}\text { Sugar } \\
\quad \text { alcohol }\end{array}$ & NDG & ++ & ++ \\
\hline Trehalose & 2 & Sugar & ++ & ++ & ++ \\
\hline Turanose & 2 & Sugar & + & ++ & ++ \\
\hline Maltulose & 2 & Sugar & NDG & ++ & ++ \\
\hline Isomaltulose & 2 & Sugar & NDG & ++ & ++ \\
\hline Galactinol & 2 & $\begin{array}{l}\text { Sugar } \\
\text { alcohol }\end{array}$ & NDG & NDG & No information \\
\hline Cellobiose & 2 & Sugar & + & + & No information \\
\hline Gentiobiose & 2 & Sugar & NDG & + & No information \\
\hline Lactose & 2 & Sugar & ++ & ++ & No information \\
\hline Melibiose & 2 & Sugar & ++ & ++ & No information \\
\hline Lactulose & 2 & Sugar & ++ & ++ & No information \\
\hline Maltotriose & 3 & Sugar & ++ & ++ & No information \\
\hline Panose & 3 & Sugar & NDG & ++ & No information \\
\hline Isomaltotriose & 3 & Sugar & NDG & ++ & No information \\
\hline Maltotetraose & 4 & Sugar & ++ & ++ & No information \\
\hline Raffinose & 3 & Sugar & + & ++ & No information \\
\hline Maltotriitol & 3 & $\begin{array}{l}\text { Sugar } \\
\quad \text { alcohol }\end{array}$ & NDG & NDG & No information \\
\hline Isomaltitol & 3 & $\begin{array}{l}\text { Sugar } \\
\quad \text { alcohol }\end{array}$ & NDG & ++ & No information \\
\hline Lactitol & 2 & $\begin{array}{l}\text { Sugar } \\
\quad \text { alcohol }\end{array}$ & ++ & ++ & No information \\
\hline Erlose & 3 & Sugar & NDG & NDG & No information \\
\hline Maltopentaose & 5 & Sugar & ++ & ++ & No information \\
\hline
\end{tabular}

Data of MG1655 (pAP2) which expresses aglA and aglB from K. pneumoniae are described in the reference (Pikis et al. 2006) and listed in this table for comparison to show what kinds of sugars and sugar alcohols were newly assimilated by heterologous expression of $g l v A$ and $g l v C$

$D P$ degree of polymerization, $N D G$ no detectable growth, - minimal growth, + slight growth, ++ clear growth

WC196LC harboring pCABD2 [encoding dapA24, lysC80, $d a p B$, and $d d h$ (Kojima et al. 1994; Kikuchi et al. 1997; Doi et al. 2014)] was transformed with pMW219- $\Delta$ PlacPtac4075-glvC and pTWV229-self-glvA-Fw. The transformant was inoculated on an LB plate containing $20 \mathrm{mg} / \mathrm{L}$ streptomycin, $100 \mathrm{mg} / \mathrm{L}$ ampicillin, and $50 \mathrm{mg} / \mathrm{L}$ kanamycin and incubated at $37{ }^{\circ} \mathrm{C}$ for $24 \mathrm{~h}$. Colonies were scratched off, suspended in saline, and adjusted to an $\mathrm{OD}_{620}$ of 15. Next, $250 \mu \mathrm{L}$ of the cell suspension was added to $5 \mathrm{~mL} \mathrm{L-}$ lysine production medium containing $16 \mathrm{~g} / \mathrm{L}$ glucose, $1.6 \mathrm{~g} / \mathrm{L}$ maltose and/or isomaltose and/or $1.6 \mathrm{~g} / \mathrm{L}$ panose, $1 \mathrm{~g} / \mathrm{L}$ $\mathrm{MgSO}_{4}$ heptahydrate, $24 \mathrm{~g} / \mathrm{L}\left(\mathrm{NH}_{4}\right)_{2} \mathrm{SO}_{4}, 1 \mathrm{~g} / \mathrm{L} \mathrm{KH}_{2} \mathrm{PO}_{4}$, $2 \mathrm{~g} / \mathrm{L}$ yeast extract, $0.1 \mathrm{~g} / \mathrm{L}$ isoleucine, $12 \mathrm{mg} / \mathrm{L} \mathrm{FeSO}_{4}$ heptahydrate, $9.6 \mathrm{mg} / \mathrm{L} \mathrm{MnSO}_{4}$ pentahydrate, $30 \mathrm{~g} / \mathrm{L} \mathrm{CaCO}_{3}$ (as dry heat-sterilized powder), $20 \mathrm{mg} / \mathrm{L}$ streptomycin, $100 \mathrm{mg} / \mathrm{L}$ ampicillin, and $50 \mathrm{mg} / \mathrm{L}$ kanamycin $(\mathrm{pH} 7.0$ with $\mathrm{KOH})$. Cells were then cultivated at $37{ }^{\circ} \mathrm{C}$ for $41 \mathrm{~h}$ with reciprocal shaking at $120 \mathrm{rpm}$. Glucose and L-lysine were assayed by a biotech analyzer (AS310; Sakura Si Co., Ltd., Tokyo, Japan). Maltose, isomaltose, and panose were measured using an ICS-3000 Ion Chromatography System with a CarboPac PA1 column (Dionex, CA, USA).

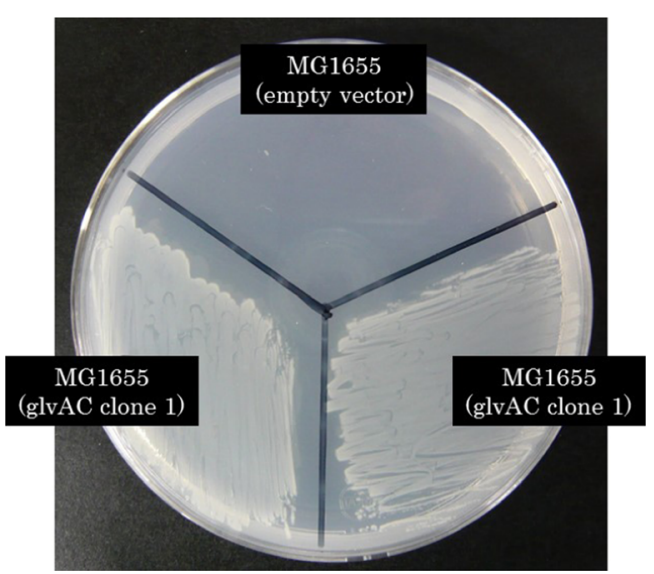

Fig. 3 Growth of E. coli recombinants on M9 solid medium containing panose as a sole carbon source. Two clones were tested in the case of MG1655 (glvAC) 


\section{Results}

Evaluation of the functions of GlvA and GlvC from B. subtilis in E. coli GlvA and GlvC have been reported to be involved in the assimilation of maltose in B. subtilis (Yamamoto et al. 2001; Thompson et al. 1998). We constructed the plasmids pTWV229-self-glvA-Fw and pMW219- $\Delta$ Plactac-glvC-R2 for the expression of $g l v A$ and $g l v C$ from B. subtilis in E. coli. The growth of the E. coli MG1655 recombinant harboring both of the plasmids on M9 medium containing isomaltose was severely limited (data not shown). However, after prolonged incubation $(45 \mathrm{~h}$ ) of the recombinant at $37{ }^{\circ} \mathrm{C}$ on the isomaltose medium, we found that some mutants started to form larger colonies. Because plasmids isolated from one of the mutants enabled $E$. coli to grow rapidly on medium containing isomaltose, we analyzed the DNA sequences of these plasmids. A mutation was found in the -10 region of the tac promoter (de Boer et al. 1983) (TATAAT to AATAAT) upstream of $g l v C$. This mutation is expected to reduce the expression level of $g l v C$ by affecting the binding affinity of RNA polymerase. We speculated that strong expression of GlvC, a membrane permease, may be toxic in E. coli. The mutant plasmid was renamed pMW219- $\Delta$ Plac-*tac-glvC. Next, we tested the growth of E. coli MG1655 harboring pTWV229-self-glvA-Fw and pMW219- $\Delta$ Plac-*tac-glvC plasmids in M9 liquid medium containing isomaltose as a sole carbon source. The recombinant could grow on isomaltose efficiently, whereas $E$. coli harboring the empty vector plasmids could grow only on glucose (Fig. 1).

Simultaneous assimilation of glucose and isomaltose by $\boldsymbol{g l v} \boldsymbol{A}$-expressing and $\boldsymbol{g l v} \boldsymbol{C}$-expressing $\boldsymbol{E}$. coli To test whether the $E$. coli recombinant could assimilate isomaltose without catabolite repression, we used M9 medium containing an excess amount $(1.8 \mathrm{~g} / \mathrm{L})$ of isomaltose or maltose supplemented with a small amount $(0.2 \mathrm{~g} / \mathrm{L})$ of glucose (Loomis and Magasanik 1967). In this medium, cell growth would stop temporarily at an $\mathrm{OD}_{600}$ of $0.1-0.2$ if the strain consumed glucose first (showing diauxic growth). The $E$. coli recombinant showed relatively slow but smooth cell growth, without characteristics of diauxic growth (data not shown), suggesting that the E. coli recombinant could assimilate isomaltose without catabolite repression. Then, to demonstrate this phenomenon more clearly, we measured sugar concentrations during cultivation on M9 minimal medium containing $1.0 \mathrm{~g} / \mathrm{L}$ maltose and glucose or $1.0 \mathrm{~g} / \mathrm{L}$ isomaltose and glucose. The $E$. coli carrying empty vector did not assimilate maltose or isomaltose in the presence of glucose (Fig. 2a, b), because E. coli assimilates maltose under the control of catabolite repression (Dean et al. 1990; Boos and Shuman 1998) and cannot assimilate isomaltose. On the other hand, the recombinant assimilated maltose or isomaltose in the presence of glucose (Fig. 2c, d). Surprisingly, the recombinant preferentially assimilated
Fig. 4 Utilization of maltose, isomaltose, and panose in the L-lysineproducing model strain. a Accumulation of L-lysine in the L-lysine production medium supplemented with glucose or glucose combined with maltose, isomaltose, and panose at the end of fermentation. b Residual maltose, isomaltose, and panose in the culture broth at the end of fermentation. Values are the means of more than three independent samples. SE bars represent the standard error of the mean calculated with Excel software. WC196LC (pCABD2) harboring the empty vector plasmids, pTVW229 and pMW219-Aplac (empty vector); WC196LC (pCABD2) harboring the $g l v A$-expressing and $g l v C$-expressing plasmids, pTWV229-self-glvA-FW and pMW219- $\Delta$ Plac-Ptac4075-glvC ( $g l v A C)$; N.D. not detected, $N A$ no addition

isomaltose over glucose (Fig. 2d). These results indicated that the heterologous expression of $g l v A$ and $g l v C$ conferred upon the cells the ability to assimilate maltose and isomaltose even in the presence of glucose.

Evaluation of the substrate specificity of GlvA and GlvC in $\boldsymbol{E}$. coli Pikis et al. reported that that expression of aglA and aglB from $K$. pneumoniae in E. coli allowed the cells to assimilate $\alpha$-methyl-glucoside, isomaltose, trehalulose, turanose, maltulose, leucrose, and isomaltulose (Pikis et al. 2006). To investigate whether the heterologous expression of $g l v A$ and $g l v C$ enabled $E$. coli to assimilate other types of carbon sources, particularly panose, we performed growth tests using M9 solid medium supplemented with various types of sugars and sugar alcohols as a sole carbon source. We tested glucose, $\alpha$-methylglucoside, sucrose, maltose, isomaltose, maltitol, trehalose, maltulose, isomaltulose, galactinol, cellobiose, gentiobiose, lactose, melibiose, lactulose, maltotriose, panose, isomaltotriose, maltotetraose, raffinose, maltotriitol, isomaltitol, lactitol, erlose, and maltopentaose (Table 3 and Fig. 3). Our results showed that the recombinant could assimilate many types of sugars and sugar alcohols, including $\alpha$-methyl-glucoside, isomaltose, turanose, maltulose, and isomaltulose, which had been reported to be assimilated by AglA and AglB (Pikis et al. 2006). In contrast, galactinol, maltotriitol, and erlose could not be assimilated by the recombinant. Interestingly, the recombinant was able to assimilate trisaccharides, such as panose and isomaltotriose. Moreover, $\beta$-linked disaccharides such as sucrose and gentiobiose were also assimilated by the recombinant. It is an unexpected result because GlvA is classified as a 6-phospho- $\alpha$-glucosidase (Yip et al. 2007).

The expression of either $g l v A$ or $g l v C$ alone is not sufficient to confer upon the recombinant the ability to assimilate any of the tested sugars and sugar alcohols except $\alpha$-methyl-glucoside. It is known that $\alpha$-methyl-glucoside is transported by PtsG of E. coli with concomitant phosphorylation (Pikis et al. 2006). GlvA can hydrolyze the phosphorylated $\alpha$-methyl-glucoside, conferring the ability to grow on the medium containing $\alpha$-methyl-glucoside.

A common chemical structure among the substrates assimilated by the GlvA-expressing and GlvC-expressing 


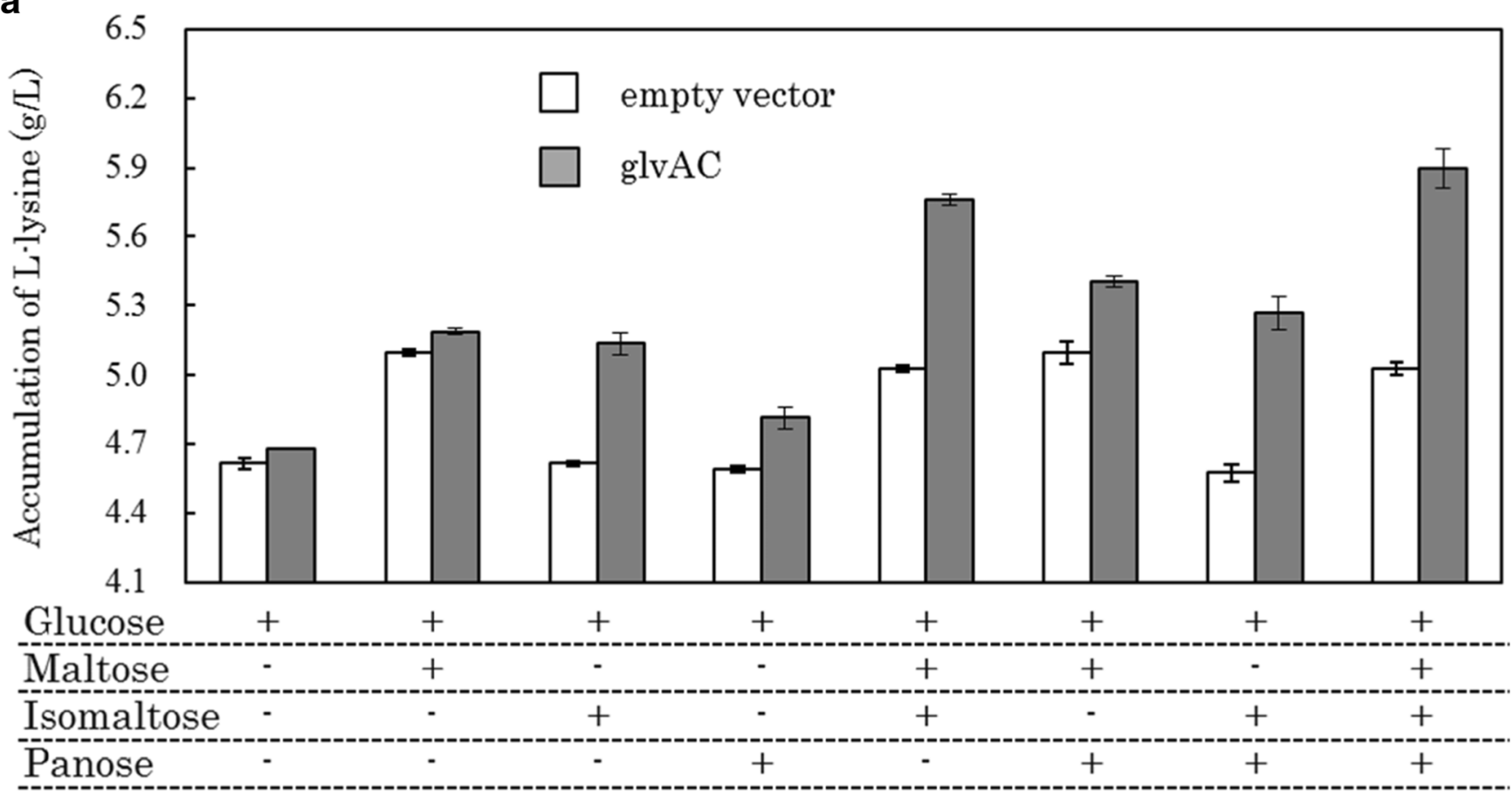

b

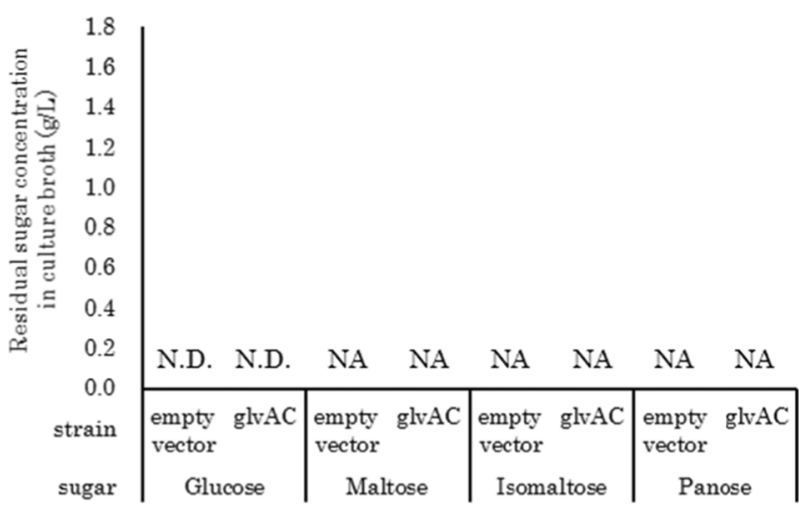

[Supplemented sugar; glucose $(16 \mathrm{~g} / \mathrm{L})$ and

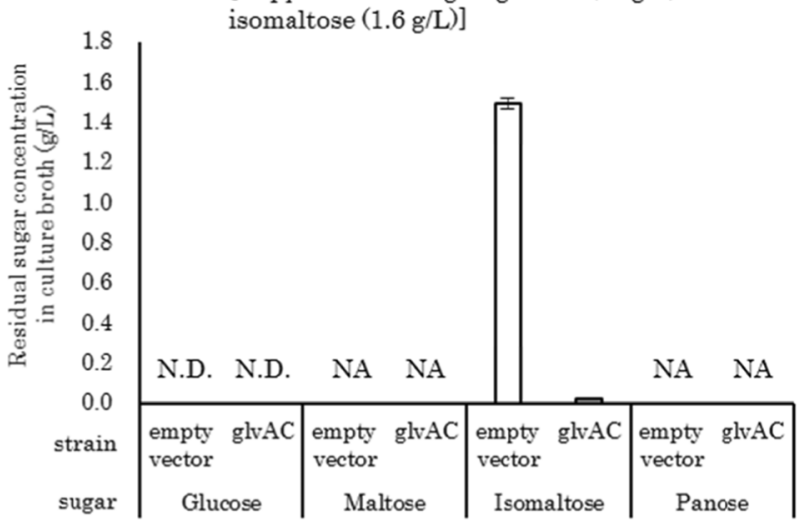

[Supplemented sugar; glucose $(16 \mathrm{~g} / \mathrm{L})$ and maltose $(1.6 \mathrm{~g} / \mathrm{L})]$

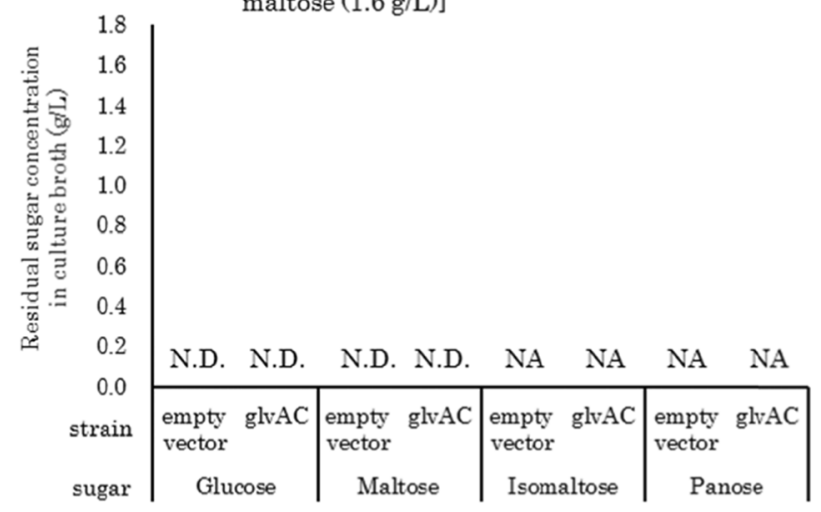

[Supplemented sugar; glucose $(16 \mathrm{~g} / \mathrm{L})$ and panose $(1.6 \mathrm{~g} / \mathrm{L})]$

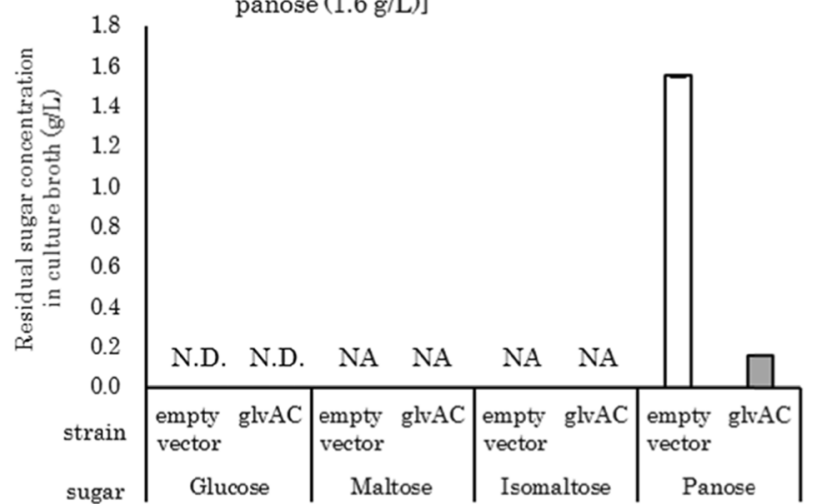



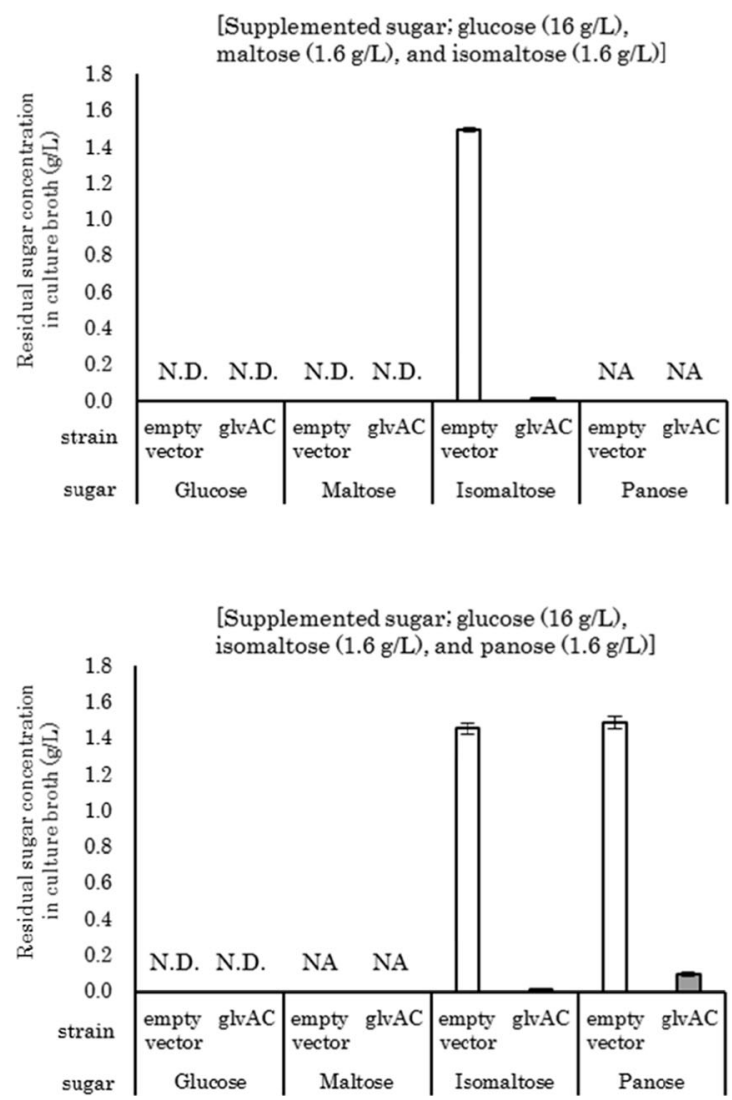

Fig. 4 (continued)

recombinant was the presence of glucose at one terminal of the sugar or sugar alcohol. Therefore, GlvC appeared to recognize the glucose unit of the sugar or sugar alcohol and transport the unit with concomitant phosphorylation of the glucose terminal. Moreover, GlvA may hydrolyze the 6'phospho-sugars and sugar alcohols to release glucose 6-phosphate. This is the first report to show expansion of the sugar substrates of $E$. coli to trisaccharides by heterologous expression of 6-phospho- $\alpha$-glucosidase and PTS components.

\section{Utilization of isomaltose and panose using GlvA and GlvC} in an L-lysine-producing model strain To evaluate the effects of isomaltose and panose utilization on fermentation efficiency, we introduced the plasmids to an L-lysine-producing E. coli strain WC196LC (pCABD2) (Kojima et al. 1994; Kikuchi et al. 1997; Doi et al. 2014). The recombinant was cultivated on L-lysine production medium supplemented with glucose or glucose combined with isomaltose, panose, or maltose (as a control). Additionally, media containing different combinations of the above saccharides were also prepared and used for L-lysine production tests. L-Lysine accumulation in the culture broth of $E$. coli WC196LC (pCABD2) harboring the empty vector plasmids was increased by approximately $0.5 \mathrm{~g} / \mathrm{L}$ only when maltose, which can be assimilated intrinsically by $E$. coli, was contained in the medium in addition to
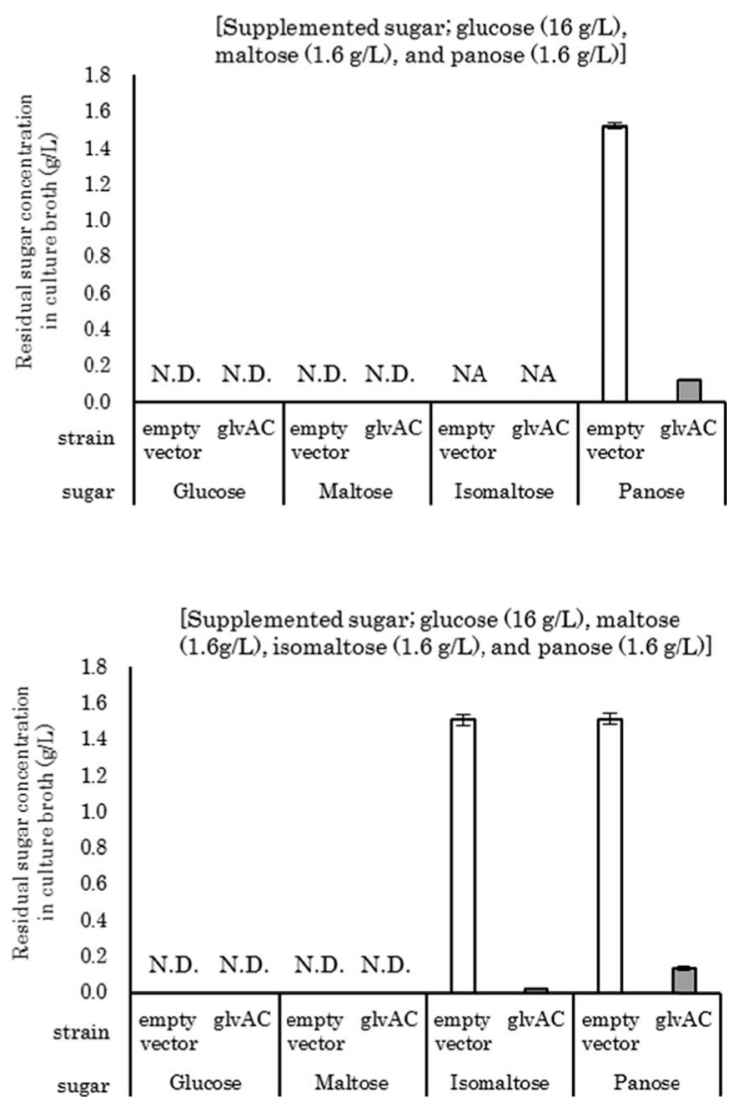

glucose (Fig. 4a). In contrast, the L-lysine production by the recombinant was increased when maltose, isomaltose, and panose were all contained in the medium. In the case of isomaltose utilization by the recombinant, L-lysine accumulation in the culture broth was increased by approximately $0.5 \mathrm{~g} /$ $\mathrm{L}$; in contrast, in the case of panose, it was increased by approximately $0.2 \mathrm{~g} / \mathrm{L}$, showing lower utilization efficiency compared with that for maltose and isomaltose (Fig. 4a). Residual sugar analysis (Fig. 4b) indicated that about $98 \%$ of supplemented isomaltose and $90 \%$ of panose were consumed by the recombinant. Although small amounts of isomaltose and panose remained in the culture broth, the assimilation of isomaltose and panose was clearly enhanced by the introduction of $g l v A$ and $g l v C$. These results showed that isomaltose and panose could be utilized as carbon sources and converted to L-lysine, suggesting that the heterologous expression of $g l v A$ and $g l v C$ could increase the efficiency of glucose feedstock utilization.

\section{Discussion}

The PTS is composed of the phosphohistidine carrier protein (HPr), the enzyme I (EI) component, and the enzymes EIIA, EIIB, and EIIC. Although heterologous expression 
of $g l v A$ (encoding phospho- $\alpha$-glucosidase) and $g l v C$ (encoding EIICB) conferred upon E. coli the ability to assimilate isomaltose, panose, and various sugars and sugar alcohols, the combination of GlvA and GlvC did not provide all the components needed to produce PTS activity, functioning only as an EIICB enzyme. HPr and EI are not specific to particular sugars, and EIIAs also do not have strict substrate selectivity for each sugar and EIICB. For example, EIIA ${ }^{\text {Glc }}$ can interact with glucosePTS and trehalose-PTS (Postma et al. 1993). Pikis et al. reported that AglA, a homolog of GlvC, interacts with EIIA $^{\text {Glc }}$, which is encoded by the endogenous $\mathrm{crr}$ gene in E. coli (Pikis et al. 2006). Therefore, GlvC is also likely to interact with EIIA ${ }^{\text {Glc }}$ of $E$. coli. We disrupted the $c r r$ gene and tested whether the heterologous expression of $g l v A$ and $g l v C$ allowed the mutant to assimilate isomaltose. The crr mutant harboring the $g l v A$ and $g l v C$ plasmids could not grow on M9 medium containing isomaltose as a sole carbon source (data not shown). Our results suggested that GlvC (a single-chain polypeptide of EIIB and EIIC) derived from the gram-positive bacterium $B$. subtilis could associate with EIIA ${ }^{\text {Glc }}$ of E. coli, similar to AglA of $K$. pneumoniae.

In industrial production of valuable compounds with E. coli, purified sugars are rarely used due to high cultivation cost, and hence, various sugar mixtures are used as carbon sources (Gokarn et al. 2014; Eiteman et al. 2008). However, assimilation of many sugars starts sequentially after consumption of glucose with lag phase, resulting in the extension of culture time and decrease of productivity (Eiteman et al. 2008; Aidelberg et al. 2014) due to carbon catabolite repression (Görke and Stülke 2008). In order to overcome this problem, several researchers have attempted to confer upon $E$. coli the ability to assimilate arabinose (Hernández-Montalvo et al. 2001), xylose (Dien et al. 2002; Hernández-Montalvo et al. 2001), and maltose (Tsujimoto et al. 2006) even in the presence of glucose. For example, Hernández-Montalvo used a mutant devoid of the phosphotransferase system to escape catabolite repression. In this study, we demonstrated that the heterologous expression of $g l v A$ and $g l v C$ under constitutive promoter allows $E$. coli to assimilate maltose and isomaltose in the presence of glucose. Surprisingly, the recombinant could also assimilate various other sugars and sugar alcohols, including several trisaccharides. This genetic engineering expanded the metabolizable sugars of E. coli and could increase product yield when using glucose feedstock. We demonstrated that an L-lysine-producing $E$. coli harboring $g l v A$ and $g l v C$ converted isomaltose and panose to L-lysine efficiently. This approach should increase the efficiency of industrial fermentation using $E$. coli and would facilitate full utilization of valuable carbohydrate resources.
Acknowledgements We are grateful to Dr. Hisao Ito of Process Development Laboratories, Research Institute for Bioscience Products $\&$ Fine Chemicals, Ajinomoto Co., Inc. for providing technical advice.

\section{Compliance with ethical standards}

Funding Nothing.

Conflict of interest The authors declare that they have no conflict of interest.

Ethical approval This article does not contain any studies with human participants performed by any of the authors.

Open Access This article is distributed under the terms of the Creative Commons Attribution 4.0 International License (http:// creativecommons.org/licenses/by/4.0/), which permits unrestricted use, distribution, and reproduction in any medium, provided you give appropriate credit to the original author(s) and the source, provide a link to the Creative Commons license, and indicate if changes were made.

\section{References}

Aidelberg G, Towbin BD, Rothschild D, Dekel E, Bren A, Alon U (2014) Hierarchy of non-glucose sugars in Escherichia coli. BMC Syst Biol 8:133

Boos D, Shuman H (1998) Maltose/maltodextrin system of Escherichia coli: transport, metabolism, and regulation. Microbiol Mol Biol Rev 62:204-229

Chaplin MF, Bucke C (1994) Chapter 4: production of glucose syrup. In: Enzyme technology. Cambridge University Press

Crabb WD, Shetty JK (1999) Commodity scale production of sugars from starches. Curr Opin Microbiol 2:252-256

de Boer HA, Comstock LJ, Vasser M (1983) The tac promoter: a functional hybrid derived from the trp and lac promoters. Proc Natl Acad Sci U S A 80:21-25

Dean DA, Reizer J, Nikaido H, Saier MH Jr (1990) Regulation of the maltose transport system of Escherichia coli by the glucose-specific enzyme III of the phosphoenolpyruvate-sugar phosphotransferase system. Characterization of inducer exclusion-resistant mutants and reconstitution of inducer exclusion in proteoliposomes. J Biol Chem 265:21005-21010

Dien BS, Nichols NN, Bothast RJ (2002) Fermentation of sugar mixtures using Escherichia coli catabolite repression mutants engineered for production of L-lactic acid. J Ind Microbiol Biotechnol 29:221-227

Doi H, Hoshino Y, Nakase K, Usuda Y (2014) Reduction of hydrogen peroxide stress derived from fatty acid beta-oxidation improves fatty acid utilization in Escherichia coli. Appl Microbiol Biotechnol 98: 629-639

Eiteman MA, Lee SA, Altman E (2008) A co-fermentation strategy to consume sugar mixtures effectively. J Biol Eng 2:3

Escalante A, Salinas Cervantes A, Gosset G, Bolívar F (2012) Current knowledge of the Escherichia coli phosphoenolpyruvatecarbohydrate phosphotransferase system: peculiarities of regulation and impact on growth and product formation. Appl Microbiol Biotechnol 94:1483-1494

Gokarn R, Parsons M, Walcker D, Spencer J (2014) Batch feed process for fermenting sugars. Patent Cooperation Treaty No. WO2014093312 
Görke B, Stülke J (2008) Carbon catabolite repression in bacteria: many ways to make the most out of nutrients. Nat Rev Microbiol 6:613-624

Harwood CR, Wipat A (1996) Sequencing and functional analysis of the genome of Bacillus subtilis strain 168. FEBS Lett 389:84-87

Hassan MA, Shirai Y, Kubota A, Abdul Karim MI, Nakanishi K, Hashimoto K (1998) Effect of oligosaccharides on glucose consumption by Rhodobacter sphaeroides in polyhydroxyalkanoate production from enzymatically treated crude sago starch. J Ferment Bioeng 86:57-61

Hernández-Montalvo V, Valle F, Bolivar F, Gosset G (2001) Characterization of sugar mixtures utilization by an Escherichia coli mutant devoid of the phosphotransferase system. Appl Microbiol Biotechnol 57:186-191

Hii SL, Tan JS, Ling TC, Ariff AB (2012) Pullulanase: role in starch hydrolysis and potential industrial applications. Enzyme Res 2012:921362

Kikuchi Y, Kojima H, Tanaka T, Takatsuka Y, Kamio Y (1997) Characterization of second lysine decarboxylase isolated from Escherichia coli. J Bacteriol 179:4486-4492

Kojima H, Ogawa Y, Kawamura K, Sano K (1994) Treaty patent WO95/16042. International Patent Cooperation.

Ledl F, Schleicher E (1990) New aspects of the Maillard reaction in foods and in the human body. Ang Chem 26:565-594

Leuchtenberger W, Huthmacher K, Drauz K (2005) Biotechnological production of amino acids and derivatives: current status and prospects. Appl Microbiol Biotechnol 69:1-8

Loomis WF Jr, Magasanik B (1967) Glucose-lactose diauxie in Escherichia coli. J Bacteriol 93:1397-1401

Martin C, Smith AM (1995) Starch biosynthesis. Plant Cell 7:971-985

Miller JH (1992) A short course in bacterial genetics. Cold Spring Harbor Laboratory Press

Peters D (2007) Raw materials. Adv Biochem Eng Biotechnol 105:1-30

Pikis A, Hess S, Arnold I, Erni B, Thompson J (2006) Genetic requirements for growth of Escherichia coli K12 on methyl- $\alpha$-Dglucopyranoside and the five $\alpha$-D-glucosyl-D-fructose isomers of sucrose. J Biol Chem 281:17900-17908

Postma PW, Lengeler JW, Jacobson GR (1993) Phosphoenolpyruvate: carbohydrate phosphotransferase systems of bacteria. Microbiol Rev 57:543-594

Reizer J (1994) Novel phosphotransferase system genes revealed by bacterial genome analysis: unique, putative fructose- and glucosidespecific systems. Protein Sci 3:440-450

Sierkes M, Svensson B (1992) Process for enzymatic hydrolysis of starch to glucose. United States Patent Number: 5,162,210
Singh M, Patel SK, Kalia VC (2009) Bacillus subtilis as potential producer for polyhydroxyalkanoates. Microb Cell Factories 8:38

Smuda M, Glomb MA (2011) Novel insights into the Maillard catalyzed degradation of maltose. J Agric Food Chem 59:13254-13264

Song W, Nie Y, Mu XQ, Xu Y (2016) Enhancement of extracellular expression of Bacillus naganoensis pullulanase from recombinant Bacillus subtilis: effects of promoter and host. Protein Expr Purif 124:23-31

Takasaki Y (1988) Method for production of glucose by use of transglucosidase. United States Patent Number: 4,855,232

Thompson J, Gentry-Weeks CR, Nguyen NY, Folk JE, Robrish SA (1995) Purification from Fusobacterium mortiferum ATCC 25557 of a 6phosphoryl-O- $\alpha$-D-glucopyranosyl:6-phosphoglucohydrolase that hydrolyzes maltose 6-phosphate and related phospho- $\alpha$-D-glucosides. J Bacteriol 177:2505-2512

Thompson J, Pikis A, Ruvinov SB, Henrissat B, Yamamoto H, Sekiguchi J (1998) The gene glvA of Bacillus subtilis 168 encodes a metalrequiring, $\mathrm{NAD}(\mathrm{H})$-dependent 6 -phospho- $\alpha$-glucosidase. Assignment to family 4 of the glycosylhydrolase superfamily. J Biol Chem 273:27347-27356

Thompson J, Robrish SA, Immel S, Lichtenthaler FW, Hall BG, Pikis A (2001) Metabolism of sucrose and its five linkage-isomeric $\alpha$-Dglucosyl-D-fructoses by Klebsiella pneumoniae. Participation and properties of sucrose-6-phosphate hydrolase and phospho- $\alpha$-glucosidase. J Biol Chem 276:37415-37425

Tsujimoto N, Suzuki T, Ito H (2006) Method for producing target substance using microorganisms with reduced interactions between MalK and IIA Glc . United States Patent Number: 7,097,999

Wendisch VF, Bott M, Eikmanns BJ (2006) Metabolic engineering of Escherichia coli and Corynebacterium glutamicum for biotechnological production of organic acids and amino acids. Curr Opin Microbiol 9:268-274

Yamamoto H, Serizawa M, Thompson J, Sekiguchi J (2001) Regulation of the $g l v$ operon in Bacillus subtilis: YfiA (GlvR) is a positive regulator of the operon that is repressed through CcpA and cre. $\mathrm{J}$ Bacteriol 183:5110-5121

Yip VL, Thompson J, Withers SG (2007) Mechanism of GlvA from Bacillus subtilis: a detailed kinetic analysis of a 6-phospho- $\alpha$ glucosidase from glycoside hydrolase family 4 . Biochemistry 46 : 9840-9852

Zeigler DR, Prágai Z, Rodriguez S, Chevreux B, Muffler A, Albert T, Bai R, Wyss M, Perkins JB (2008) The origins of 168, W23, and other Bacillus subtilis legacy strains. J Bacteriol 190:6983-6995 